\title{
AN IMPROVED TRAINING PROCEDURE AS A PRECURSOR TO TESTING YOUNG CHILDREN WITH THE FRISBY STEREOTEST
}

\author{
JOHN P. FRISBY ${ }^{1}$, HELEN DAVIS ${ }^{2}$ and KEVIN McMORROW ${ }^{2}$ \\ Sheffield
}

\begin{abstract}
SUMMARY
We describe a modified version of the Frisby Stereopsis Screening Test which enables a light to be flashed behind the stereo target when the child being tested makes an appropriate pointing or reaching response. The light can be flashed to gain the interest of the child during a training phase in which they are familiarised with the test and its requirements. This phase is then followed by a test phase in which the child is encouraged to demonstrate unaided clear pointing responses to the target to gain a light flash while the plate is held in two or three different positions. This device has proved effective in increasing the chances of administering the test successfully to a sample of 30 very young children (age range $7-23$ months).
\end{abstract}

Clear evidence exists that stereopsis normally emerges between 3 and 6 months of age, ${ }^{1,2}$ and that early treatments for its failure to develop normally have a better chance of success if performed before 24 months, ${ }^{3}$ or ideally earlier. ${ }^{4}$ These considerations have led to the need for a simple means for testing for stereopsis in very young children, either as part of a screening programme or as a test to be used in standard clinical examinations.

A good stereopsis test for very young children has to meet some exacting criteria, particularly if it is to be part of a large-scale screening procedure. We argue that the test should be:

1. Based on simple, cheap, robust, and easily transportable equipment. These requirements rule out the sort of stereo rigs normally used with preferential looking techniques ${ }^{5,6}$ or dynamic

From: ${ }^{1}$ Department of Psychology, University of Sheffield, Sheffield; ${ }^{2}$ Department of Ophthalmology and Orthoptics, Royal Hallamshire Hospital, Sheffield, UK.

Correspondence to: J. P. Frisby, Department of Psychology, University of Sheffield, Psychology Building, Western Bank, Sheffield S10 2TP, UK. Fax: +44 (0114) 2766515. random dot displays. ${ }^{7}$ They also rule out the use of visual evoked potentials. ${ }^{8}$

2. Non-intrusive. This rules out the use of red/green or polarising spectacles, which young children may refuse to wear. Such spectacles have the additional disadvantage of being potentially dissociating.

3. Repeatable without risk of the child learning to make the correct response from memory, or from cues other than those deriving from stereopsis. Repeated presentations are desirable in order to check doubtful responses. They also make possible the inclusion of training as an integral part of testing, as will become clear later.

4. Suited to the severely limited attention spans and test understanding of very young children. Unless special steps are taken, children up to around 18-24 months of age often lose interest in standard test displays within a few seconds of their presentation, and they cannot be relied upon to understand even simple test instructions.

We know of no stereopsis test which satisfies all these criteria. This lack was the motivation for the present work. Our starting point was the Frisby Stereotest (Fig. 1) because it comes closest, ${ }^{9}$ we believe, to satisfying the above criteria. It involves natural viewing of a simple real three-dimensional object, and so it readily satisfies criteria 1 and 2 . The plate can be shown repeatedly with the target at a different position on each occasion, so the test also satisfies criterion 3. In this respect it has an advantage over the Lang Stereotest (which also does not require red/ green or polarising spectacles). The weakness of the Frisby, along with all other simple stereotests currently available, concerns criterion 4 . For many very young children their interest in the Frisby plate is so fleeting (frequently just 10-20 seconds) as to make a reliable stereopsis assessment impossible. It 


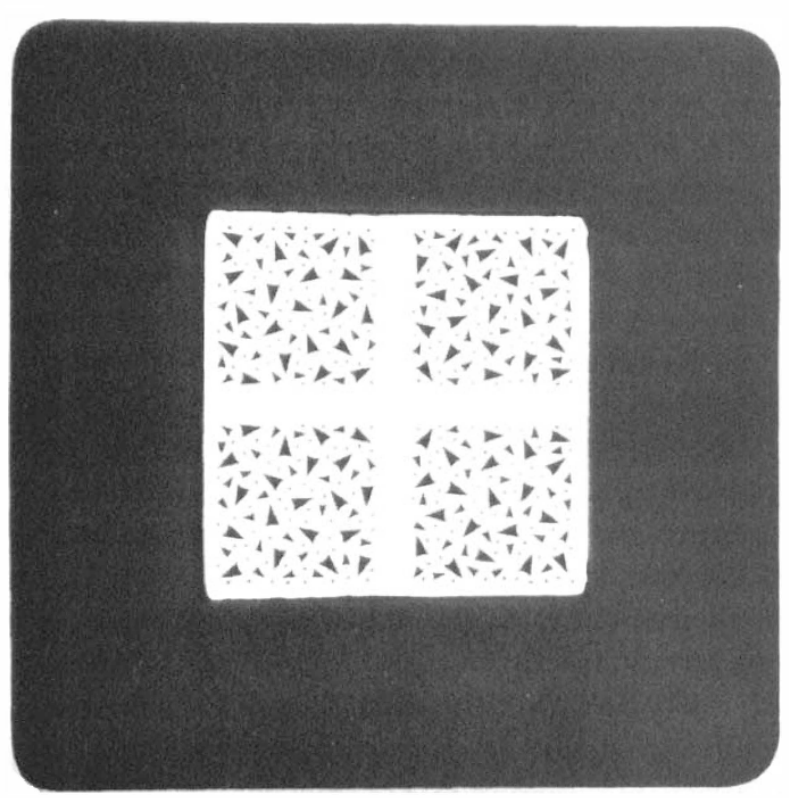

Fig. 1. The Frisby Stereotest - $6 \mathrm{~mm}$ plate. There are four squares of texture, one of which contains a roughly circular 'target' patch which, for observers with stereopsis, appears in front of its surround (or behind, if the plate is viewed from other side). This depth effect, which cannot of course be seen here, is created by having the texture elements comprising the target printed on one side of the plate, with the surround elements (and all the elements within the nontarget squares) printed on the other side of the plate. The Frisby plate is shown here mounted behind a dark (blue) plastic frame which forms the front of the Light Flash Frisby Stereotest (see Fig. 2).

becomes suitable for routine use only with children older than about 24 months. The objective in the present research is to develop the test for use in younger children.

\section{A LIGHT FLASH VERSION OF THE FRISBY STEREOTEST}

The approach we describe here is based on the idea of regarding a stereotest administration to very young children as a training session in which the child is first taught how to respond appropriately to the test plate, and then tested with it. This is feasible with the Frisby as it is designed to permit repeated presentations. It is thus possible to present it as a game in which the target has to be found afresh in a new location on each presentation. It is not often, in our experience, that users take advantage of this method of administering the Frisby, despite the instructions provided with the test. However, even presenting the Frisby in this manner does not always work satisfactorily because many young children find the plate too uninteresting to bother with for long. This can be true whatever general encouragement is given to them, including the technique of the tester taking the child's hand and pointing it at the target.

We have attempted to solve this problem by attaching to the Frisby plate a means for rewarding the young child with an 'interesting event' if they show that they have identified the target square by pointing at it or by touching it. We have experimented with two sorts of rewards to underpin the training of correct responses. An acoustic reward proved too distracting to other children, so we substituted a visual reward of a light that could be flashed behind the target. The light was a bright red l.e.d. mounted behind a piece of opal acrylic sheet, itself mounted $1 \mathrm{~cm}$ behind the $6 \mathrm{~mm}$ plate of the Frisby (Fig. 2). This modified test was framed by a piece of plain dark blue opaque acrylic which was glued to the assembly holding the opal acrylic and the 1.e.d. so that it hid the wiring, battery for the l.e.d. etc. Four button switches which could be operated silently were placed so that they could be found easily and pressed discreetly by the tester as required. The switches thus gave the tester complete control over when the light was to be flashed.

Using this Light Flash version of the Frisby, the tester's first task becomes one of teaching the child to make a suitable response by flashing the light as a reward. The child is placed on the carer's lap, facing the stereotest which is held square to the child's line of view by the tester in the usual manner. Initially, the light can be flashed when the child's hand is

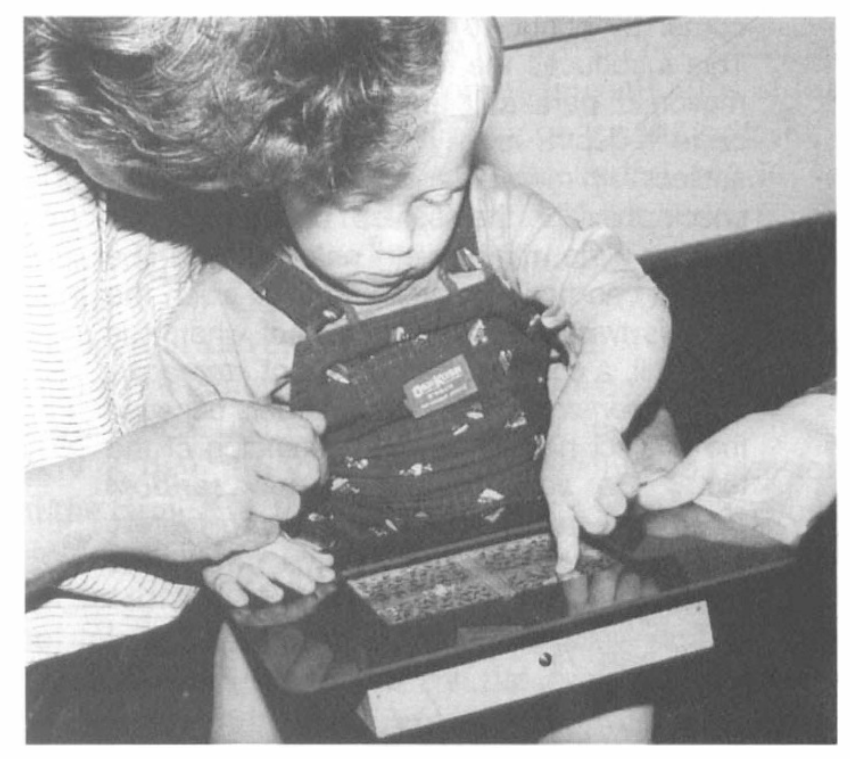

Fig. 2. A child passing the Light Flash Frisby Stereotest. This test comprises the dark frame surround shown in Fig. 1 on which is mounted a box in which is fitted the Frisby Stereotest plate. The box contains a clear translucent screen $1 \mathrm{~cm}$ behind the Frisby plate that provides a clear background against which the texture of the Frisby plate can be seen. Behind this screen is mounted a l.e.d. (also inside the box which also holds the battery and wiring). The l.e.d. is positioned behind the target square of the Frisby plate and can be flashed on and off by the tester operating button switches mounted on the box walls (see text). The child can be seen pointing to the target of the Light Flash Frisby, a response which would be rewarded by the tester (on the right of the photograph) whose hand underneath the dark frame is operating one of the button switches on the box. 
placed on the target. Reward associated with the passive initial placing of the child's hand is then gradually changed over a series of trials until the light flash reward is given only for accurate and independent touching or pointing at the target (the operant ${ }^{5,6}$ conditioning technique of 'successive approximations'). As training continues, so rewards are restricted to responses closer and closer to the one desired, until at last reward is given only for the 'correct' response. During this training phase the guiding principle should be immediacy of reward. If the light flash is delayed by more than a second or so after a desired response in the series of successive approximations then it might be taken by the child to be a reward for an unwanted response. It can be helpful for testers to demonstrate the operation of the light by touching it themselves while discreetly operating a switch, thus also encouraging a form of insight learning and/or mimicry on the part of the child.

The target should be kept in a fixed position while the child is being taught the basic requirement to touch the plate for a light flash. However, as soon as

\section{CHECKING TEST UNDERSTANDING}

(1) Twist the plate gently to and fro on a corner by about 10 degrees (as illustrated). This introduces the monocular depth cue of motion parallax which makes the circle-in-depth readily visible, even for a subject with monocular vision. (Testers should check this for themselves by viewing the twisting plate with one eye only.) Hence, if a patient can find the circle-in-depth when the plate is twisted to and fro but not when it is held still, a confident judgement of stereopsis not demonstrated can be recorded because the subject has shown understanding of the test. Be sure to use a new random position when stereopsis is being tested, and that the patient views the plate squarely with head and plate held still.

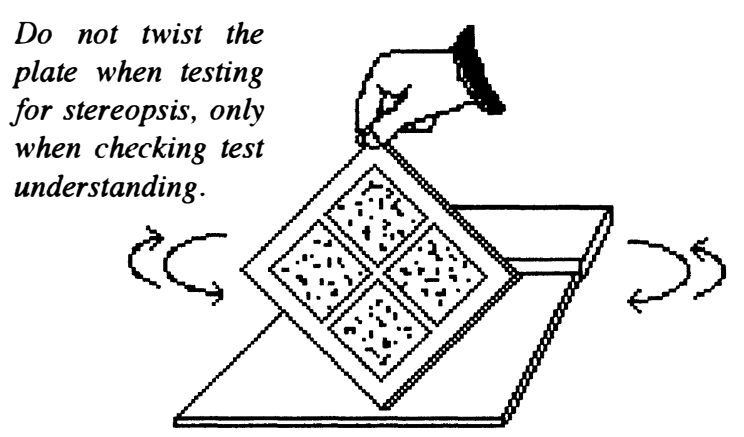

Fig. 3. Excerpt from the Instructions Booklet for the Frisby Screening Stereotest, showing how the plate can be twisted to generate a motion parallax cue to assist in test understanding (test available from Clement Clarke International Ltd, Airmed House, Edinburgh Way, Harlow, Essex $C M 202 E D, U K)$. the tester judges it appropriate, the plate needs to be rotated to a new position, so that the stereo target becomes the discriminative stimulus. The plate-toeye distance is fixed by the reach of the child and is customarily therefore about $30-40 \mathrm{~cm}$, providing a disparity for the $6 \mathrm{~mm}$ thick Frisby plate of about 900-600 arc sec. However, given the great variability in eye-to-plate distance during training, this range should be taken only as a rough guide, particularly as the goal is not assessing stereoacuity but screening for 'Stereopsis Demonstrated/Not Demonstrated'.

Following the training phase comes a final testing phase in which an assessment is made of the child's ability to make two or three clear pointing or touching responses to the stereo target in different positions unaided, except of course for continuing oral encouragement to respond. If the child can do this then the result 'Stereopsis Demonstrated' is recorded. The tester should be aware at this point of the standard precaution in using the Frisby of ensuring that the child's head is steady (by restraint if necessary) when making the final test responses.

Exactly when the training phase ends and the test phase begins is a matter for the judgement of the tester. We have found that if a child proves able to learn the task then they do so in at most about 5 minutes (often much less), but to that must be added the caveat that this generalisation is based only on the rather small sample reported here $(n=30)$.

With the standard Frisby test the judgement of 'Stereopsis Demonstrated' can sometimes be made if the child shows convincing fixation eye movements towards the target over a series of different positions. If, despite encouragement and training over as long a period as is feasible, no confident correct responses are made by the child then a judgement of 'Stereopsis Not Demonstrated' should be recorded. Such a child will normally be referred for full orthoptic examination.

As with stereo tests in general, failure to learn how to make a pointing response to obtain the flashing light can sometimes be due to failure to understand the test requirements rather than to any lack of stereopsis. A check on this possibility can be made for some children by rotating the plate gently to and fro while privoting it on one corner (Fig. 3). This form of presentation creates a strong movement parallax depth cue and a depth effect which is just as vivid as that created by stereopsis for the normal binocular observer when the plate is held still.

\section{DESIGN AND PROCEDURE}

The goal of the present study was to establish, as a precursor to a prospective screening study, whether young children aged under 24 months with normal binocular vision could be readily trained to perform correctly on the Light Flash Frisby Stereotest. We 
used a random sample of 30 young children from two local nurseries. All were recruited following standard ethical procedures for gaining written parental consent. The children (11 girls and 19 boys) were aged between 8 and 23 months when tested, with ages in months as follows: 7, 8, 9,2 $2 \times 10,3 \times 11,13,2$ $\times 14,4 \times 15,17,3 \times 18,5 \times 19,2 \times 20,21,2 \times 22$, 23. All were first given the Light Flash Frisby. This was immediately followed by presentation of a second version of this test in which the test plate was supported in a small table placed on the ground in front of the seated child. It was thought this means of presentation might convey some benefits for very young children. In fact none became very apparent and as the results were identical to those from the version described here no further details will be reported. A cover test and the prism reflex test were given on a subsequent day to all but two children who were unavailable; this indicated they had no discernible manifest deviations. (A recent study ${ }^{10}$ has produced evidence indicating that the Frisby Screening Test (6 $\mathrm{mm}$ plate) and the Lang II Test cannot be used safely as predictors of a visual acuity deficit as some have suggested. This is not a surprising result as far as the Frisby is concerned, because its texture was specifically designed to have a mixture of coarse as well as fine elements, so that poor vision would not necessarily impede a demonstration of stereopsis.) All tests were given in the standard nursery playroom. This was chosen to provide a secure and known environment for the children. Their customary carers were present and they often helped with the testing - for example, by having the child sit on their lap.

\section{Qualitative Results}

\section{RESULTS}

All children found the Light Flash Frisby test sufficiently interesting for their attention to be engaged long enough to make a stereopsis assessment. The training regime proved highly effective, with almost all children enjoying the game of learning how to 'find the magic light'. Training and testing together rarely took more than a few minutes for most children who proved able to give clear positive responses. Some children needed much longer and some eventually failed altogether (see below) after as long a time as their interest could be held (sometimes for as long as 10 minutes with suitable pauses and encouragement). Our clear view is that the new version of the Frisby is a significant improvement over the standard Frisby Screening test for this age group, judging from the experience of J.P.F. and H.D. over many years in giving the standard Frisby test to similar groups of children.

\section{Quantitative Results}

Of the 30 children, 27 passed the Light Flash Frisby stereotest. We call these children correct negatives, i.e. they were correctly picked out by the test as not having a stereo deficit (recollect that all but two of the children were revealed as normal by the orthoptic examination; and these two, who were not available for the orthoptic examination, passed the stereotest).

Three of the 30 children failed the stereotest. We call these children false positives, or equivalently false referrals. The key question needing discussion is why these children failed to pass the stereotest despite passing the orthoptic examination. We will comment on each case in turn.

Louise (age 7 months) was the youngest child in the sample. It could conceivably be that at the time of testing her stereopsis was not developed to the stage where it could give a suitable basis for performance on the stereotest. We rather doubt that this was the case, given evidence that reasonable stereopsis is usually in place by 6 months. Instead, although this is only an impression, we suspect that her failure related to her stage of intellectual development, coupled with the fact that she had a bad cold when tested. Although she proved interested in the light flash, it was necessary to lift the test square on to her line of view to distract her attention from the altogether more compelling stimulus of the tester's face. During the training phase she occasionally touched the target but she failed to do so convincingly in the test phase. Although there will presumably be some children as young as Louise for whom a positive result can be obtained, the intellectual development of children 7 months old cannot in general be presumed to be sufficient to learn a task of the present kind. The conclusion we draw is that although it may be sensible on occasion in the clinic to attempt a stereo test with such a young child because a positive response would be helpful diagnostically, in general a negative response cannot be taken as a sign of a stereopsis deficit. This conclusion is supported by the fact that we have previously found children of 8 months or younger unable to pass the Frisby Stereotest reliably in a study which used an acoustic training signal instead of the light flash. ${ }^{11}$

Rebecca (age 11 months) gave the general impression that, like Louise, her failure arose from a lack of the necessary intellectual development. It supports the conclusion that failures on behavioural stereotests of children under about 1 year old cannot be assumed to be due to a stereopsis deficit.

Langston (age 19 months) was unusually shy and seemed very immature compared with other children of his age in the nursery. He seemed able to grasp the principle of the test during training but when in the 
test phase his hand just wandered over the test surface without producing a clear identification of the target. At the same time he looked up to the tester, seemingly for a sign of encouragement. This pattern of responding occurred twice. Our tentative conclusion is that he failed through lack of understanding what was required despite the training, and we intend to re-test him in a few months time to discover whether he has developed intellectually to the point of being able to pass the test. For the age at which he was tested (19 months), he may be an example of a child who will always be a false referral for this form of testing. Obviously, from such a small sample it is impossible to estimate the overall percentage of the false referrals of this type that would be produced by a screening programme based on the present test.

\section{DISCUSSION}

We consider that the Light Flash Frisby Stereotest can be used by orthoptists wishing to test for the presence of stereopsis in children under 2 years of age. The improved training regime extends the age range for confident assessments of Stereopsis Demonstrated, and the test is easy to use. The goal of the present study was to establish whether young children with stereopsis could be easily trained to demonstrate their stereopsis using the Frisby and a light flash reward. It did not attempt a formal comparison between the Light Flash and the standard Frisby Stereotest so our assessment of the modified test will remain subjective until a formal study is conducted, even though that assessment is founded on considerable clinical experience in administering the two tests.

The Light Flash Frisby test is just as suitable for 3to 4-year-old children as for younger ones, and it may increase for all pre-school children the prospects of effective stereopsis screening.

In view of the value of the training regime we would recommend that users of the Frisby adopt training as routine practice for any child for whom a positive result, defined as two or three clear-cut, correct, speedy responses of pointing at, looking at, or describing the target, is not immediately evident.

The Light Flash Frisby Stereotest (patent applied for) is commercially available (details from first author, address on title page). It can be supplied either with a $6 \mathrm{~mm}$ Frisby plate, or without if testers wish to fit their existing $6 \mathrm{~mm}$ Frisby plate into the new Light Flash Frisby Stereotest housing. Further development work on this new test ${ }^{12}$ has led to refinements in which the target can be presented with monocular cues during training without needing to use the technique shown in Fig. 3 of rotating the test plate.

We are extremely grateful to the staff of the Endcliffe and Nether Edge nurseries in Sheffield for allowing us access to their children. We also thank the children themselves, and their parents who granted permission for their participation. Michael Port, Ian Dales and Len Hetherington gave valuable assistance with equipment and photography. David Buckley made useful comments on the manuscript.

Key words: Frisby Stereotest, Stereopsis, Vision screening.

\section{REFERENCES}

1. Birch EE, Shimojo S, Held R. Preferential looking assessment of fusion and stereopsis in infants aged 1-6 months. Ophthalmol Vis Sci 1985;26:366-70.

2. Leguire ED, Rogers GL, Bremer DL. Visual evoked response binocular summation in normal and strabismic infants: defining the critical period. Invest Ophthalmol Vis Sci 1991;32:126-33.

3. Smith JC, Atkinson J, Anker S, Moore AT. A prospective study of binocularity and amblyopia in strabismic infants before and after corrective surgery: implications for the human critical period. Clin Vision Sci 1991;6:335-53.

4. Wright KW, Edelman PM, McVey JH, Terry AP, Lin M. High grade stereo acuity after early surgery for congenital esotropia. Arch Ophthalmol 1994;112:9139.

5. Birch EE, Hales LA. Operant assessment of stereoacuity. Clin Vision Sci 1989;4:295-300.

6. Ciner EB, Scheiman MM, Schanelklitsch E, Weil L. Stereopsis testing in 18 to 35 month old children using operant preferential looking. Optom Vision Sci 1989;66:782-7.

7. Dunlop DB, Dunlop P, Roger AN. A wider concept of stereopsis. Br Orthoptic J 1980;37:71-81.

8. Neill RA, Dunlop P, Dunlop DB, Fenton B, Dunlop C. Stereoscopic evoked responses to crossed and uncrossed disparity accompanying simulated refractive error. Br J Orthoptics 1988;72:759-63.

9. Broadbent H, Westall C. An evaluation of techniques for measuring stereopsis in infants and young children. Ophthalmic Physiol Opt 1990;10:3-7.

10. Smith GM. Evaluation of the Frisby Screening Plate and Lang II Stereotest in primary vision screening in pre-school children. Br J Orthoptics 1995;52:1-4.

11. Frisby JP, Davis H, Higham L. Using an audible reward in a training regime for a modified version of the Frisby Stereotest. Internal Research Memorandum, Department of Psychology, University of Sheffield, Sheffield UK, 1994.

12. Davis H, Frisby JP. Assessing the Light Flash Frisby Stereotest for testing young children with strabismus. 22nd Annual Meeting of the American Association for Pediatric Ophthalmology and Strabismus, Snowbird, Utah, March, 1997. 